\title{
Europe needs a strategy to fight kidney disease
}

\author{
Funding would be well spent, both in human terms and in reducing the financial burden.
}

Sir-Many people are unaware that autosomal dominant polycystic kidney disease $(\mathrm{ADPKD})$ is one of the most common life-threatening genetic diseases on the planet, with an incidence of about 1 in 1,000 . It affects some 12.5 million people worldwide, making it twice as common as multiple sclerosis and five times as common as cystic fibrosis. On top of the human cost, it causes a financial drain on health provision, including dialysis and transplantation services. In the United States the impact of ADPKD has long been recognized, yet in Europe funding for research into this disease is sorely lacking. This needs to change.

Last year, ADPKD was the only kidney disease singled out by the US Senate Committee on Appropriations for special attention. In 2003, $\$ 1.72$ billion was appropriated for the National Institute of Diabetes and Digestive and Kidney
Diseases, which has a strategic plan to tackle ADPKD and free up more than 3,000 places on kidney transplant lists, saving $\$ 2$ billion annually in ADPKDrelated costs. The research budget for the major PKD charity in the United States, the PKD Foundation (www.pkdcure.org), is currently more than $\$ 2.5$ million.

The contrast with Europe is striking. In Britain, the Medical Research Council spent nothing on ADPKD in 2001-02 and

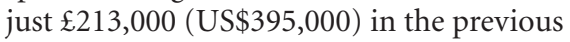
year. Sadly, there are fewer than five specialist ADPKD research groups in Britain, even though global research has accelerated since the identification of the gene products responsible a decade ago. The UK charity the National Kidney Research Fund considers ADPKD research a strategic objective, yet it lacks sufficient high-quality applications to fund more than four ADPKD-focused projects from a total of 80 awards. Britain's PKD Charity (www.pkdcharity.co.uk), of which I am a trustee, is in its infancy and currently has no opportunity to sponsor research.

Our European neighbours are faring no better. Budget cuts in France have hit medical research hard, including ADPKD studies, so laboratories are being depleted of their brightest young associates for lack of funding. How the next round of funding from the European Union, the Framework 6 programme, will respond to the US lead in this area is yet to be seen. Within the Framework's calls for research to tackle major disease, there is no particular focus on ADPKD, despite a clear emphasis on rare genetic conditions. Without such strategic thinking, European ADPKD research will continue to suffer.

\section{Peter J. Lockyer}

Signalling Programme, Babraham Institute, Babraham, Cambridge CB2 4AT, UK

\section{Celebrating supernovae that changed the world}

Sir - Further to J. L. Heilbron and W. F. Bynum's Commentary "1904 and all that" (Nature 426, 761; 2003), two anniversaries connected with supernovae are worth noting. First, there was the discovery of the Crab supernova by some Chinese astrologers in 1054 (this would be $9.5 \leftarrow$ in the units used by Heilbron and Bynum). The second was the discovery of one of the renaissance supernovae, the SN 1604, by Johannes Kepler - who is mentioned in the Commentary, but for different reasons.

The Greeks thought of the sky as unchanging and did not expect to find new phenomena in the heavens. Even the comets were thought of as essentially terrestrial. However, the Chinese did not have these reservations, and kept a track of any changes in the night sky, which were believed to affect the fortunes of the country and the emperor. They have always been wonderful record keepers, and the Crab supernova is one of the many 'guest stars' they have discovered during the past 2000 years. The Crab is now known as the 'Rosetta Stone' of modern astrophysics, because its extraordinary features provide clues to numerous astrophysical phenomena, including supernova remnants, pulsars and highenergy emissions.

As your Commentary noted, Kepler and Galileo changed physics and astronomy in fundamental ways, but the general populace could only be convinced of the need to revise overall Greek thinking about the heavens by more direct evidence - if at all. It is said that the appearance of the two renaissance supernovae (the first one found by Tycho Brahe in 1572) in the European skies helped to generate acceptance of these new scientific ideas about the heavens.

P. R. Vishwanath

Indian Institute of Astrophysics, Sarjapur Road. Koramangala, Bangalore 560 034, India

\section{Was Watson and Crick's model truly self-evident?}

Sir - I am compelled to reply to the comments of Nature's emeritus editor John Maddox (Nature 426, 119; 2003) concerning Nature's editorial decision not to send the Watson and Crick paper (Nature 171, 737-738; 1953) for peer review. Maddox's retrospective comment "the Crick and Watson paper could not have been refereed: its correctness is self-evident" represents the wisdom of hindsight. To suggest that any model is correct and self-evident on its face leads to acceptance without questioning.

In response to Maddox's comment that the paper could not have been refereed, several capable reviewers were available Rosalind Franklin, Maurice Wilkins or Erwin Chargaff, for example.

Even Watson and Crick had serious doubts about the correctness of their DNA structure. The 1953 Nature paper expresses self doubt: "previously published X-ray data on deoxyribose nucleic acid are insufficient for a rigorous test of our structure ... it must be regarded as unproved until it has been checked against more exact results".

In the F. L. Holmes book Meselson, Stahl and the Replication of DNA (Yale Univ. Press, New Haven, 2001), the author notes that Watson "suffered from periodic fears that the structure might be wrong and that he had made an ass of himself. ... Watson really did harbor serious doubts about the validity of their structure for DNA, before and after he and Crick published their first paper in Nature".

In a letter dated 12 March 1953 to Max Delbrück at Caltech, Watson states: "The X-ray pattern approximately agrees with the model, but since ... we have no photographs of our own ... this agreement in no way constitutes a proof of our model. We certainly are a long way from proving its correctness.... In the next day or so Crick and I shall send a note to Nature proposing our structure as a possible model, at the same time emphasizing its provisional nature and the lack of proof in its favor."

Stanley Scher

PO Box 9456, Berkeley, California 94709, USA

\section{correspondence}

Contributions to Correspondence may be submitted to corres@nature.com. They should be no longer than 500 words, and ideally shorter. Published contributions are edited. 